\title{
How Mexican Americans Achieve Equality in K-12 Education in the United States?
}

\section{Li Liu}

School of Foreign Languages, Shandong Jiaotong University, Jinan, Shandong, 250000, China

\begin{abstract}
This article examined how Mexican Americans in the United States fought for their education equality in the K-12 public education system in the 20th century. Mexican Americans who suffered from segregated education and exclusion from administration at the beginning of last century launched legal battles, acquired administrative power and teaching positions, and conducted social activities. Their fighting enabled them to access unsegregated K-12 education. Although inequality still exists in the education system, the Mexican Americans' endeavor for education equality is unwavering.

Keywords: Mexican Americans; segregation; equality

DOI: $10.36012 /$ fhe.v1i1.891
\end{abstract}

$\mathrm{I}$ $\mathrm{t}$ is important to examine the Mexican Americans experience of segregation in public K-12 schools, and how Mexican Americans achieve equality in K-12 education, especially in the Southwestern region of the United States in the 20th century, which will improve the education environment of the Mexican Americans, and the development of K-12 education in the Unite States. According to Gutié rrez (2010), Mexicans who migrate to America and consider the United States as their home country, endeavor to assimilate into the mainstream culture. The second generation of Mexicans is considered as the Mexican Americans, who contributed to the victory of the Second World War and fought for their rights after the war, and their children were the third generation of Mexicans, the Chicanos.

\section{Segregation of the Mexican American Students in K-12 Education}

The public education in the United States dedicates to the following three purposes, citizenry education for the social democracy development, culture and language assimilation of the immigrants, and workforce preparation for the economy (MacDonald, 2013). The education system caters to the needs of economy and society and educated the immigrants. The Mexican Americans attach great emphasis on education "as a means of economic, political, social, and upward mobility" (MacDonald, 2013, p. 307). However, the Mexican immigrants and Mexican Americans, were separated from the whites in the public places and politics, and the segregation was "forced" and "intentional" after the "Treaty of Guadalupe Hidalgo" after 1848 (Valencia, 2008).

At the end of nineteenth century, the labor industries in the Unites States attracted legal and illegal immigrants from Mexico. From 1910 to 1930, the number of immigrants from Mexico reached over one million (Gonzá lez, 1999). Public schools were considered as vehicles to Americanize these immigrants by the Anglos, which were accepted in the Southwest (MacDonald, 2013). How to accommodate the Mexican children into the public education system brought difficulties to the limited education resources. Two solutions were proposed to solve the problem. First, they receive segregated education in Mexican schools. Second, the forced IQ tests were implemented among the Mexican children and it was believed that they had 
lower IQ than the whites, so they were incapable of equal education and career options (Gonzá lez, 1999).

The public education was dedicated to Americanizing the Mexican children who were considered as culturally defective, which would threaten Anglo culture. Americanization was demonstrated in education through the emphasis on English and the abolishment of Spanish language. Besides, in the separated schools, Mexican children received a large proportion of "industrial education" to prepare them for employment rather than college education. In the rural areas, some Mexican children were excluded from public education because they were the labor forces in the family. In the segregated schools, teachers also suffered from prejudice as they were considered as being less qualified (Gonzá lez, 1999).

According to Guajardo and Guajardo (2004), school segregation was permitted by the Plessy v. Ferguson decision in 1896. According to San Miguel (2015), Mexican Americans had been provided with "limited, substandard, and inferior" (p. 7) public education due to their social status, linguistic characteristics and culture from 1900 to the year 1960. The segregation was "lack of uniformity" and "arbitrary" (Sá nchez, 1951, p. 30). Only children with Spanish names were segregated in the schools. Both the school administrators and the Anglo parents opposed Mexican Americans to share schools with the white children (MacDonald, 2013).

San Miguel(2013) explained that Mexican Americans were considered as inferior race with backward culture by political officials and the public. Mexican American students felt unwanted and suffered from political opposition to their schooling, low economic status, and inequitable access to education. They had "unequal facilities" and "imbalanced and subtractive curriculum” (San Miguel, 2015, p. 7) with less academic directions and training. Mexican Americans had low enrollment and retention, and it showed no improvement in the 1970s and 1980s (Pachon \& Moore, 1981).

\section{Exclusion of Mexican Americans from E- ducation Administration}

During that period, Mexican Americans had been excluded from critical positions in public education system and the shaping of education content, and their participation had been denied. Voting is considered as a resource to attain administration power. However, the Mexican Americans were excluded from voting and they were intimidated or experienced violence to access voting (Meier \& Stewart, 1991).

The Mexican Americans "have the lowest levels of formal education" (Meier \& Stewart, 1991, p. 41). They received less finance support. The Mexican children were separated in almost all the school districts by different means. For example, according to Meier and Stewart (1991), first, there were "Mexican-only schools" (p. 60) for Mexican Americans. In the 1920s, Mexican Americans were not allowed to receive secondary education. In 1944, nearly half of Mexican Americans children had no access to education. Although the Americanization of Mexican Americans enabled them to go to public schools, their admission into public schools was still hindered by the local officials. Even in the 1950s, not few Mexican American students still had segregated education. In Arizona and California, English was mandatory and no Spanish was allowed at schools (Meier \& Stewart, 1991).

According to Sá nchez (1951), segregation is contrary to the education purpose. It undermines the interests and confidence of Mexican children to attend and finish their school education.

\section{How Mexican Americans Achieve Equality in K-12 Education?}

According to Gutié rrez (2010), the Chicanos pursued equality and power using five ways "revolt, litigation, protest, electoral work, and building coalitions/alliances” (p. 26). Concerning education, Chicanos adopted "nonviolent protests and demonstrations" (Gutié rrez, 2010, p. 26) such as walkouts to acquire education equality. Chicanos are eager to acquire their power and rights with their votes through the involvement in elections, and strive for pass of a large number of legal cases regulating the rights of the Chicanos such as the voting rights, the bilingual education rights.

\subsection{The importance of education is explained.}

Meier and Stewart (1991) stated that "of all the forums for discriminations, discrimination in education is the most invidious" (p. 2). Education promotes upward social mobility and elevates the social origins. Education discrimination will lead to inequality of all aspects in life, especially the income which is closely related to the quality of education one receives. Education is cru- 
cial for the Mexican Americans for the following three reasons. First, poverty tends to perpetuate if Mexican Americans who suffer from poverty have no access to education. Second, Mexican Americans mainly consist of younger people who need more education. Third, the continuing immigration from Mexico will make this issue a persistent problem(Meier \& Stewart, 1991).

Face with the segregation, Gonzá lez (1999) stated that "If oppression is never permanent, it is only so because the victims rise up against their oppressors" (p. 71). Mexicans Americans devoted to the dismantling of educational segregation because they placed value on the importance of education. Although the Mexican Americans "have the highest poverty rate of any ethnic group" (Zambrana \& Hurtado, 2016, p. 4), they still manage to motivate their children to receive education.

\subsection{Mexican Americans fight for equality in K-12} education.

According to Meier and Stewart (1991), faced with segregation, the Mexican Americans first filed legal suits so that they can be admitted to white schools, which was "a" major tactic" the Mexican Americans employed to fight for equality in education. For example, Valencia (2008) identified 35 lawsuits to desegregate the Mexican Americans, most of which were initiated by the Mexican Americans themselves.

3.2.1 Legal battles for equality in K-12 education.

Compared with other Hispanic groups, Mexican Americans have longer history living in the United States, and they made greater development in politics, so they are supposed to be the first group among the Hispanics to fight for education rights (Meier \& Stewart, 1991). The League of United Latin American Citizens (LULAC), established by the middle class of Mexican Americans, filed suit against segregation in Texas to claim for equal access to schools as the whites in 1930.

Although they won the agreement of the court, they still failed because the school board denied their request. Then in 1945 in California, LULAC again appealed for equal rights in education. Although they won the case and the segregation was banned in California, the segregation of Mexican American students did not improve.

Sá nchez (1951) acknowledged the two influential legal decisions about the segregation of Mexican children: "Mendez case in California and the Delgado case in Texas" (p. 9). The Delgado case in 1948 ruled that it is illegal to segregate the Mexican children in schools. The two cases established that segregation violated the constitution. In 1954, Guajardo and Guajardo (2004) stated that the "Brown v. Board of Education” (p. 501) case legally reversed the public schools' segregation. However, the Mexican Americans were excluded from this act. Besides, some states were slow to implement it. For example, it was until 1970 when Texas enforced the integration of public schools, which can be attributed to the endeavor for equality in education of Mexican Americans. In the 1950s, there were cases filed to eliminate segregation without satisfactory results. In 1968, the Mexican-American Legal Defense and Education Fund (MALDEF) were established, who also fight against education segregation. In 1970, Cisneros v. Corpus Christi Independent School District regulated that the education rights of the Mexican Americans should be protected by the constitution (Meier \& Stewart, 1991, p. 69).

According to Delgado Bernal (1999), although the legal case eliminated segregation, Mexican children actually continued to be segregated. For example, widespread segregation of Mexican children was implemented in Texas. The following reasons explained the continual of segregation. The Mexican culture was deficient to the whites, and the Mexican children were considered as inferior, and not worth education investment. They were not allowed to speak Spanish in schools because the suppression of the language was actually to control the Mexican Americans in the United States. LULAC also supported the spread use of English among the Mexican Americans to assimilate into the white-dominant society. The Bilingual Education Act was approved in 1968 to sponsor the use of Spanish language.

3.2.2 Administrative power and teaching positions.

Meier and Stewart (1991) proposed that to acquire education equality for the Mexican Americans, they need to have access to the school board, administrative positions, teaching positions and other decision-making positions. Political positions should be distributed equitably because the education administration has the power to define educational decisions. In addition, Mexican American teachers are also important to the education equality for Mexican American students because the teachers can capable of implementing the educational decisions (Meier \& Stewart, 1991). They can 
also have a better understanding of the Mexican American students, and play as role models for the Mexican American students.

To combat education segregation, Mexican Americans officials with Mexican heritage also established institutions for public education teachers to train teachers for the Mexican American students. For example, not few normal universities trained bilingual teachers for the Mexican American students to teach them in English and Spanish (MacDonald, 2013).

It was until 1975 when the discrimination against Mexican Americans was recognized by the Supreme Court in Keyes v. Denver case to abolish the segregation in public schools. However, unevenly-distributed educational funding in different school districts created financial inequality to the Mexican Americans (Meier \& Stewart, 1991). In Texas and California, Mexican Americans fought for legislative equality so that the state courts in nine states all required ensuring the education funding to be equally distributed (Meier \& Stewart, 1991).

\subsubsection{Social activities for equality in K-12 education.}

Beside the legal suits and administrative endeavor to strive for equality in education for Mexican Americans, there are also some social activities conducted by them. In 1910, in San Angelo of Texas, the Mexican parents protested that their children were assigned to segregated school and then had a boycott of the high school, which lasted for five years without any fruitful results (MacDonald, 2013).

In the 1960s, the Mexican youth played a critical role in the movement for equality. They strived for improving the quality of public education (Delgado Bernal, 1999). For example, in 1968, the walkout of students in one high school in South Texas enabled the power shift to Mexican Americans in that region, thus the structure of power had been challenged (Guajardo \& Guajardo, 2004). In California, the students also had walkout to fight for their rights to have bilingual education and incorporation of Chicano culture, etc. There were not only protests and walkouts of the Mexican Americans but also funds provided by "private foundations and government agencies" (MacDonald, 2013, p. 319).

The Mexican American students attended Catholic schools and Protestant schools, and the graduates contributed to confront the racism. The activists also established "community-based schools" to contest segregation (San Miguel, 2015, p. 9).

\section{The Current Situation of Mexican Amer- icans K-12 Education}

The second generation of Mexican Americans encountered discrimination, which can be demonstrated in the academic grouping of them into "low-ability and mentally retarded classes” (Meier \& Stewart, 1991, p. 79), and the over frequent discipline of the Mexican American students, hence the high dropouts of Mexican American students. In addition, compared with the white students, the Mexican American students do have lower academic achievement.

There are improvements on the educational conditions and the academic achievement of Mexican American students. Despite their efforts, Mexican Americans had the lowest ranking in the high school graduation compared with other ethnic groups, and the rate for dropout was the highest in 1990 (Bonner, Pacino, \& Hardcastle Stanford, 2011). Mexican Americans had dissatisfactory performances in schools. They lag behind the whites in English reading and mathematics. The Mexican American English language learners now frequently receive high stake tests. Mexican culture and language are important to the Mexican Americans so they should be promoted instead of being suppressed. The endeavor for equality in K-12 education for Mexican Americans cannot cease but should be continued.

\section{References}

[1] Bonner, P. J., Pacino, M. A. Transition from paraprofessionals to bilingual teachers: Latino voices and experiences in education[J]. Journal of Hispanic Higher Education, 10(3): 212-225.

[2] Delgado Bernal. Chicana/o education from the civil rights era to the present $[\mathrm{J}]$. Harvard Educational Review Reprint Series, (32):77-108.

[3] Gonzá lez, G. G. Segregation and the education of Mexican children [J], Harvard Educational Review Reprint Series (32): 53-76.

[4] Guajardo, M. A., \& Guajardo, F. J. The impact of Brown on the Brown of South Texas: A micropolitical perspective on the education of Mexican Americans in a South Texas community[J]. American Educational Research Journal, 41 (3): 501-526.

[5] Gutié rrez, J. á . The Chicano movement: Paths to power [J]. The Social Studies, 102(1): 25-32.

[6] MacDonald, V. M. Demanding their rights: The Latino struggle for educational access and equity. American Latinos and the Making of the United States: A Theme 
Study.

[7] Meier, K. J., \& Stewart, J. The politics of Hispanic education: Un paso pa'lante y dos pa'tras [J]. Albany, NY: SUNY Press.

[8] Pachon, H. P., \& Moore, J. W. The ANNALS of the American Academy of Political and Social Science [M], 454(1): 111-124.

[9] San Miguel, G. Chicana/o struggles for education: Activism in the community (Vol. 7)[M].

[10] San Miguel, G. A common passion: Mexican Americans and school reform in the U.S. during the $20^{\text {th }}$ century and early $21^{\star}$ century[J]. Journal of South Texas, 28 (1): 6-17.

[11] Sá nchez, G. I. Concerning segregation of Spanish-speaking children in the public schools (University of Texas, Austin, 1951)[J]. Education and the Mexican American, (1974).

[12] Valencia, R. R. Chicano students and the courts: The Mexican American legal struggle for educational equality.

[13] Zambrana, R. E., \& Hurtado, S. Mexican Americans' educational barriers and progress: Is the magic key within reach?. PERSPECTIVAS: Issues in Higher Education Policy and Practice. Issue No. 5. 